\title{
ZAMAN PENCERELİ BÖLÜNMÜŞ-DAĞITIMLI ARAÇ ROTALAMA İLE AFET SONRASI YARDIM MALZEMESİ DAĞITIMI PLANLAMASI
}

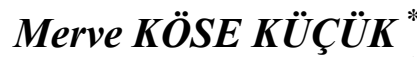 \\ Fatih ÇAVDUR *
}

Alınma: 25.05.2018; düzeltme: 19.10.2019 ; kabul: 19.04.2019

\begin{abstract}
Öz: Bu çalışmada, afet sonrası geçici-afet-müdahale tesislerinden afetzedelere yardım malzemesi dağııım problemi için bir çözüm yaklaşımı önerilmektedir. Problem, literatürde bulunan Zaman Pencereli Bölünmüş-Dağıtımlı Araç Rotalama Problemi'ne uyarlanarak modellenmiştir. Önerilen çözüm yaklaşımı, yakın tarihli başka bir çalışmada geliştirilen stokastik programlama modeli sonuçlarını kullanarak, yardım malzemelerinin, önceden konumlandırılmış geçici-afet-müdahale tesislerinden afetzedelere en az maliyet (uzaklık) ile dağıtımının yapılmasını amaçlamaktadır. Söz konusu stokastik programlama modelinin sonuçları kullanılarak, başlangıç dağıtım problemi, her birisi önerilen çözüm yaklaşımıyla Zaman Pencereli Bölünmüş-Dağıtıml Araç Rotalama Problemi olarak çözülen daha küçük boyutlu altproblemlere (bağımsız taşıma problemleri) bölünmüştür. Problem boyutundaki küçülmenin çözüm süresi açısından katkılar sağladığı, Bursa'nın büyük bir ilçesi için geliştirilen örnek olay kullanılarak oluşturulan her bir alt-problemin kişisel bir bilgisayarda saniyeler içinde çözülebildiği görülmektedir.
\end{abstract}

Anahtar Kelimeler: Yardım malzemesi dağııımı, geçici-afet-müdahale-tesisi, araç rotalama problemi, bölünmüş-dağıtımlı araç rotalama problemi

\section{Post-Disaster Relief Supplies Distribution Planning via Split-delivery Vehicle Routing with Time Windows}

Abstract: In this study, a solution approach is proposed for the problem of post disaster relief supplies distribution from temporary disaster-response facilities to the disaster-victims. The problem is modeled by adapting the Split-Delivery Vehicle Routing Problem with Time Windows from the literature. The proposed solution approach uses the results of a stochastic programming model developed in recent study, and is aimed at distributing relief supplies to disaster victims with the minimum cost (distance) from the pre-positioned temporary-disaster-response facilities allocated via the corresponding stochastic programming model. Using the results of the stochastic programming model, the initial distribution problem is divided into smaller sub-problems (i.e., independent transportation problems) each of which is solved using the proposed solution approach as a Split-Delivery Vehicle Routing Problem with Time Windows. It is noted that the reduction in the problem size provides positive contributions in terms of the solution time as each sub-problem generated using a case study developed for a large district of BursaTurkey can be solved in a few seconds on a personal computer.

Keywords: Relief supplies distribution, temporary-disaster-response facility, vehicle routing problem, split-delivery vehicle routing problem

\footnotetext{
* Uludağ Üniversitesi, Mühendislik Fakültesi, Endüstri Mühendisliği Bölümü, Nilüfer, 16059 Bursa

İletişim Yazarı: Merve KÖSE KÜÇÜK (mervekose@uludag.edu.tr)
} 


\section{GİRIŞ}

Son yıllarda, dünyada doğal afetlerin meydana geliş sıklığında bir artış gözlenmektedir. Ülkemizde yaşanan doğal afetlerin türüne göre meydana gelen kayıların \%66's1 depremler, $\% 15$ 'i seller, \%10'u toprak kaymas1, \%7'si kaya düşmesi, \%2'si de meteorolojik olaylar sonucu oluşmaktadır (Genç, 2007). Türkiye'de diğer doğal afetlere oranla en sık meydana gelen ve etkileri itibariyle en yıkıcı olan afet türü depremdir (Erdik ve diğ., 2003). Geçmişte ülkemizde yaşanan depremler ve potansiyel deprem tehdidi göz önüne alındığında, deprem felaketinin yıkıcı etkilerinin en aza indirilebilmesi için, ülkemizin etkin bir afet yönetimine ihtiyacı olduğu görülmektedir. Bu bağlamda, afet yönetimi, afetlerin önlenmesi ve zararlarının azaltılması, afet sonucunu doğuran olaylara zamanında, hızlı ve etkili olarak müdahale edilmesi ve afetten etkilenen topluluklar için daha güvenli ve gelişmiş yeni bir yaşam çevresi oluşturulabilmesi için toplumca yapılması gereken topyekun bir mücadele süreci olarak tanımlanmaktadır (Afet Yönetimi Terimleri Sözlüğü, 2014). Afet yönetimi, afet öncesi, sıras1 ve sonrasında yapılan çalışmaları ve bu çalışmaların koordinasyonunu sağlayan tüm faaliyetleri kapsamaktadır. Afet öncesi afet müdahale tesislerinin yerleşimi, bu tesislerde bulunması gereken yardım malzemesi miktarının belirlenmesi, afet sırasında ve sonrasında afet müdahale ekiplerinin sevk ve idaresi, müdahale ve tahliye planlarının oluşturulması gibi faaliyetler, afet yönetimi kapsamında yapılan çalışmalara örnek olarak gösterilebilir. Afet yönetimi zarar azaltma, hazırlık, cevap ve iyileşme olmak üzere dört aşamadan oluşmaktadır (Galindo ve Batta, 2013). Geçmişte yapılan çalışmalar, afet operasyonları aşamaları dikkate alınarak incelendiğinde, çalışmaların çoğunun azaltma aşaması ile ilgili olduğu gözlenmiş olmakla birlikte (Altay ve Green, 2006), son yıllarda, cevap aşamalarını veya birden fazla aşamayı içeren çalışmaların daha çok sayıda olduğu görülmektedir (Galindo ve Batta, 2013). Bu çalışmalar genel olarak, ilk aşamada acil müdahale tesislerinin konumlarının belirlenmesi (hazırlık) faaliyetlerini içerirken, ikinci aşamada ise dinamik yerleşim ve yardım malzemesi dağıtımı (cevap) faaliyetlerini içermektedir.

Dünyada FEMA (Federal Emergency Management Agency), Kızılhaç (Red-Cross) gibi uluslararası kuruluşlar afet yönetimi faaliyetlerinden sorumlu kuruluşlardır. Türkiye'de ise Başbakanlığa bağlı Afet ve Acil Durum Yönetim Başkanlığı (AFAD) ve Kızılay afet yönetimi faaliyetlerinden sorumlu resmi kuruluşlardır. Olası bir afet sonrası AFAD ve Kızılay gibi merkezi ilk yardım ekiplerinin afet bölgesine ulaşmalarında meydana gelebilecek çeşitli aksaklıklar ve gecikmeler sebebiyle, afetzedelerin gündelik yaşamlarına devam etmelerini sağlamak amacıyla yapılan afet operasyonları faaliyetlerinin önemi her geçen gün artmaktadır. $\mathrm{Bu}$ nedenle, afet bölgesinde merkezi ilk yardım ekiplerini destekleyecek alternatif yerel kaynakların kullanımının araştırılması konusu da giderek önem kazanmakta ve yapılan çalışmalarda bu konuya eğilimin artmasını sağlamaktadır. Bu kapsamda ortaya çıkan geçiciafet-müdahale tesisleri yerleşim problemi, merkezi ilk yardım ekipleri tarafından afetzedelere yardım malzemesi dağıtımı yapılana kadar geçen sürede, afetzedelerin temel ihtiyaçlarını gidermek amacıyla kurulacak geçici tesislerin afet bölgesine konumlandırılması ve kapasitesinin belirlenmesi olarak tanımlanabilir. Cavdur ve diğ. (2016) tarafından yapılan çalışmada, geçiciafet-müdahale tesisleri yerleşim probleminin çözümü için iki-aşamalı stokastik programlama modeli geliştirilmiştir. Geliştirilen bu model ile geçici-afet-müdahale tesislerinin konumlarının ve kapasitelerinin belirlenmesinin ardından ortaya çıan bir diğer problem ise, bu tesislerde depolanan yardım malzemelerinin afetzedelere en az maliyet (uzaklık) ile ulaştırılması problemidir. $\mathrm{Bu}$ çalışmada, afet sonrası ortaya çıkan yardım malzemelerinin afetzedelere dağıtım problemi, Zaman Pencereli Bölünmüş-Dağıtımlı Araç Rotalama Problemi (ZPBD-ARP) olarak modellenmiş ve problemin çözümü sağlanmıştır. Cavdur ve diğ. (2016) tarafindan geliştirilen modelin sonuçları kullanılarak, başlangıç dağıtım problemi, her biri önerilen çözüm yaklaşımıyla ZPBD-ARP olarak çözülen daha küçük boyutlu bağımsız alt-taşıma problemlerine ayrılmıştır. 
Çalışmanın diğer bölümleri şu şekilde organize edilmiştir. İkinci bölümde konu ile ilgili literatür taramasına yer verilmiştir. Üçüncü bölümde, çalışmada kullanılan metodoloji hakkında detaylı bilgi verilmiş ve ZPBD-ARP modeli açıklanmıştır. Dördüncü bölümde uygulama sonuçları ve bu sonuçların analizinden bahsedilmiştir. Son bölümde ise çalışma hakkında genel bir değerlendirme yapılmıştır.

\section{LITERATÜR ARAŞTIRMASI}

Afet sonrası afetzedelere ihtiyaçları oranında yardım malzemesinin en az maliyet (uzaklık) ile taşınması problemi ve bu problemin çözümü için yapılan çalışmalar, insani lojistik (humanitarian logistics) faaliyetlerinin önemli bir kısmını oluşturmaktadır. Bu kapsamda son yıllarda, afet operasyonları yönetimi çalışmalarıyla birlikte, insani lojistik çalışmalarına olan ilginin de giderek arttığ 1 görülmektedir. Bu çalışmalar genel olarak, afet sonrasında afetzedelerin temel ihtiyaçlarını karşılamak amacıyla yapılan lojistik faaliyetlerinin planlanmasını içermektedir.

Geleneksel/Ticari tedarik zinciri ile insani lojistik uygulamaları karşılaştırıldığında dikkate alınan performans parametreleri açısından birçok fark gözlenmektedir. Örneğin, ticari tedarik zincirinde daha çok finansal göstergeler önemli iken, insani lojistik faaliyetlerinde daha çok insani unsurlar (can kayıplarının azaltılması, yaralılara en kısa sürede ulaşılması, vb.) ön plana çıkmaktadır. Ticari tedarik zincirinde amaç kar optimizasyonu olarak belirlenirken, insani lojistik faaliyetleri kar amacı gütmeyen kuruluşlar tarafından yürütülmektedir. İnsani lojistik ve ticari tedarik zinciri uygulamalarının detaylı karşılaştırması için Beamon ve Balçık tarafından yapılan çalışma (Beamon ve Balçık, 2008) incelenebilir. İnsani lojistik alanında yapılan bir diğer literatür tarama çalışması, farklı bir bakış açısı kullanılarak Natarajarathinam ve diğ. (2009) tarafından yapılmıştır. Bu çalışmanın amacı, kriz anında tedarik zincirini yönetmede yapılan mevcut uygulamaları ve bu uygulamaları konu edinen çalışmaları araştırmaktır. Çalışmada aynı zamanda, kriz döneminde tedarik zinciri uygulamaları konusunda yapılacak gelecek çalışmalar için çeşitli öneriler sunulmaktadır.

İnsani lojistik alanında yapılan çalışmalarda sıklıkla lojistik ağı tasarımı dikkate alınmaktadır. Bu tür çalışmalara örnek olarak Nagurney ve diğ. (2011) tarafindan yapılan çalışma gösterilebilir. Bu çalışmada, afet veya acil durumlarda beklenen salgınlar ve ulusal güvenliği etkileyen saldırılar gibi kritik durumlar için tedarik ağı tasarımı ele alınmıştır. Afet sonrası dağıtım ağı tasarımı probleminin ele alındığı bir diğer çalışma olarak Nolz ve diğ. (2011) tarafından yapılan çalışma gösterilebilir. Bu çalışmada ele alınan çok amaçlı modelde, risk azaltılması, maksimum düzeyde kapsama ve dağıtım zamanının en küçüklenmesi hedeflenmiştir. Risk haritaları ile afet sonrası hasarlı yolların olasılıkları belirlenerek, ele alınan problemin iteratif bir algoritma ile çözümü sağlanmıştır.

İnsani lojistik uygulamalarının konu edinildiği birtakım çalışmalarda ise ağ tasarımı kapsamında afet öncesi tesis yerleşim problemi dikkate alınmıştır. Genellikle bu çalışmalarda, hem afet öncesi faaliyetleri hem de afet sonrası faaliyetleri içerecek şekilde iki veya daha fazla aşamadan oluşan çözüm yaklaşımları önerilmektedir. Bu çalışmalarda genellikle dikkate alınan hedefler; en az sayıda tesis kurulması, en kısa mesafede/sürede yardım malzemesi dağıtımı, riskin en aza indirilmesi vb. olarak sıralanabilir. Örneğin, Chan ve diğ. (2001) çalışmalarında, belirsiz talep yapısını dikkate alarak, çoklu-depo ve çok-araçlı yerleşim-rotalama problemini ele almıştır. Yazarlar tarafından, çalışmanın ilk aşamasında dağıtım merkezlerinin konumlarının belirlenmesi, ikinci aşamasında merkezlerin her birine doğru miktarda teslimat aracının yerleştirilmesi, üçüncü aşamasında ise talepleri oranında afetzedelere en kısa sürede teslimat yapılması olmak üzere üç aşama dikkate alınmaktadır. Barbarosoğlu ve Arda (2004) çalışmalarında, tesis yerleşim problemini ele alarak, problemin çözümü için stokastik programlama yaklaşımı önermişlerdir. Önerilen yaklaşımın birinci aşamasında, yardım malzemelerinin en kısa sürede ve en az maliyetle taşınması amaçlanırken, ikinci aşamada ise, yerleşimi yapılan tesislerde bulunacak stok düzeyine karar verilmiştir. Yi ve Özdamar (2007) 
tarafından yapılan çalışmada, tıbbi malzeme taşınmasını sağlayan afet müdahale ekipleri yerleşimi problemi ele alınmıştır. Çalışmanın amacı, malzemelerin bulundukları depolardan, afet bölgesindeki dağıtım merkezlerine, aynı zamanda yaralıların acil müdahale birimlerine en kısa sürede ulaştııılmasını sağlamaktır. Önerilen yaklaşımın ilk aşamasında, dağıtımı yapılacak tıbbi malzeme miktarları belirlenmiş, ikinci aşamada ise araçların ilgili rotalara atanmalarını sağlayan bir algoritma geliştirilmiştir. Rawls ve Turnquist (2010) çalışmalarında, afet öncesi tesis yerleşim problemini ele alarak, problemin çözümü için iki-aşamalı stokastik karışık tamsayılı programlama modeli geliştirmiş̧tir. Çalışmanın amacı, afet sonrası belirsiz durumlar altında önceden yerleşimi yapılacak acil durum malzemelerinin depo yerlerini ve miktarlarını belirlemek ve bir acil müdahale planlama aracı geliştirmektir. Mete ve Zabinsky (2010) tarafından yapılan çalışmada, tıbbi malzemelerin depolanacağı tesislerin konumlarını belirleme ve belirlenen bu tesislerde tutulacak stok düzeyine karar vermek amacıyla iki-aşamalı stokastik programlama modeli geliştirilmiştir. Önerilen çözüm yaklaşımının birinci aşamasında tesis konumları ve gerekli kapasite miktarları belirlenirken, ikinci aşamada, senaryo parametresi olarak tesislerden hastanelere dağıtımı yapılacak tıbbi malzeme miktarı dikkate alınmıştır. Ayrıca, tıbbi malzemelerin en kısa sürede en uygun araçla taşınmasını sağlayan bir karışık tamsayılı programlama modeli geliştirilmiştir. Sheu (2010) tarafından yapılan çalışmada, tesis yerleşim problemi ele alınarak, problemin çözümü için stokastik programlama yaklaşımı önerilmiştir. Önerilen yaklaşımın ilk aşamasını; tesis konumlandırılması ve kapasite kararları oluştururken, ikinci aşamasında ise; yardım malzemesi dağıtımı ve afetzede taşınması kararları verilmektedir.

İnsani lojistik kapsamında yapılan bazı çalışmalarda ise afet sonrası operasyonlar ve bu operasyonların koordinasyonu dikkate alınmıştır. Bu çalışmalarda genel olarak dikkate alınan hedefler; yardım malzemelerinin en kısa sürede ulaştırılması, ölü ve yaralı sayısının en aza indirgenmesi, tahliye süresinin en küçüklenmesi vb. olarak sıralanabilir. Çalışmalarda dikkate alınan belirsizlik unsurları ise genellikle afetzede sayısı, yıkılan veya hasarlı bina sayıs1, müdahale ekiplerinin uygunluğu, yolların güvenilirliği vb. olarak belirlenmiştir. Bu çalışmalara örnek olarak; Salman ve Gül (2014) tarafından yapılan çalışmada, İstanbul'da olması muhtemel bir deprem için, yaralı taşıma problemi ele alınarak, problemin çözümü için karışık tamsayılı programlama modeli geliştirilmiştir. Geliştirilen model ile afetzedelere tıbbi bakım hizmetleri sunmak için kapasite tahsisi ve afetzede tahliye kararlarını aynı anda ve en doğru şekilde verebilen bir karar mekanizması kurulmaya çalışılmışıır. Haghani ve Oh (1996) tarafından yapılan çalışmada, zaman pencereli çok-ürünlü çok-modlu ağ akış problemi ele alınmıştır. Çalışmada malzemelerin hangi taşıma tipinde, hangi araçla, hangi rota üzerinden taşıma yapacağına karar veren bir taşıma planı oluşturulması amaciyla bir matematiksel model geliştirilerek, problemin çözümü için Lagrange gevşetmesi yöntemi kullanılmıştır. Özdamar ve diğ. (2004) tarafindan yapılan çalışmada afet lojistiği karar destek sistemine entegre edilebilecek bir planlama modeli geliştirilmiştir. Çalışmada, afet sonrası yardım malzemesi dağıtım problemi için bir taşıma planı oluşturulması amaçlanmış olup, problem ağ akış ve araç rotalama problemi olarak ele alınmış ve çözümü için Lagrange gevşetmesi yöntemi kullanılmıştır. Afshar ve diğ. (2009) tarafından yapılan çalışmada, olası bir sel felaketi sonrası en kısa sürede afet bölgesine ulaşmayı amaçlayan rotaların seçildiği bir araç rotalama modeli geliştirilmiştir. Selin şiddeti ve su basıncındaki belirsizliklerin tahmininde, Monte Carlo simülasyonu kullanılmıştır. Song ve diğ. (2009) tarafından yapılan çalışmada, afet sonrası tahliye planlama problemi ele alınmış, problemin çözümü için, afetzedelerin afet bölgesinden en kısa sürede tahliyesini gerçekleştiren rotaların bulunmasını amaçlayan bir matematiksel model geliştirilmiştir. Çalışmada ele alınan tahliye planlama problemi, belirsiz talep altında yerleşim ve rotalama kararlarını içerecek şekilde formüle edilmiştir. Adıvar ve Mert (2010) tarafından yapılan çalışmada ise, birtakım belirsiz unsurlar dikkate alınarak, uluslararası afet müdahale kurumlarının güvenilirliğini en üst düzeye çıkaracak ve en az maliyete sahip bir kurtarma planlama modeli önerilmiştir. Çalışmada dikkate alınan belirsiz bilgiler, bulanık sayılarla temsil edilerek tahliye planlama probleminin 
çözümü için çok-amaçlı bulanık matematiksel model geliştirilmiştir. Ben-Tal ve diğ. (2011) tarafından yapılan çalışmada, zamana bağlı talep belirsizliği altında acil müdahale ve dinamik tahliye problemi ele alınarak, problemin çözümü için gürbüz optimizasyon yaklaşımı önerilmiștir. Vitoriano ve diğ. (2011) tarafından yapılan çalışmada, yardım malzemesi dağıtım problemi için çeşitli kriterler (tahliye süresi, eşit dağıtım, güvenilirlik, güvenlik, vb.) belirlenmiş ve bu kriterler dikkate alınarak çok-kriterli bir optimizasyon modeli geliştirilmiştir. Geliştirilen bu model ile insani lojistik faaliyetlerinden sorumlu kuruluşlara yardımcı olmak amaciyla geliştirilmekte olan karar destek sisteminin ana unsurunun oluşturulması amaçlanmıştır. Özdamar ve Demir (2012) tarafından yapılan çalışmada, büyük ölçekli afet sonrası dağıtım ve tahliye problemi için bir hiyerarşik kümeleme ve rota prosedürü geliştirilmiştir. Çalışmada, her planlama düzeyinde talep/afetzede dügümmlerini daha küçük kümelere ayıran ve küme-rotalama probleminin en iyi çözümünü sağlayan çok-aşamalı bir kümeleme algoritması geliştirilmiştir.

Geçmişte yapılan çalışmalar incelendiğinde, insani lojistik uygulamalarında ortaya çıkan en önemli problemlerden birinin, yardım malzemelerinin afetzedelere en az maliyet ile (mesafe, süre, vb.) taşınması olduğu görülmektedir (Özdamar ve Demir, 2012). Bu yardım malzemesi taşıma probleminin bir Araç Rotalama Problemi (ARP) olarak kurgulanması ve buna bağlı olarak çeşitli çözüm yaklaşımları geliştirilebileceği görülmektedir. ARP, tüm dügümlerin talebini araç kapasitesi doluncaya kadar karşılayarak, en az maliyetle (taşıma süresi, araç sayısı, vb.) depoda başlayan ve depoda biten optimal rotaların bulunmasını amaçlamaktadır. ARP'de her düğüm yalnızca bir kez ve bir araç tarafindan ziyaret edilir ve her araç sınırlı bir kapasiteye sahiptir (Belfiore ve diğ., 2008). Düğümlerin yalnızca bir kez ziyaret edilebilmesi pratikte her zaman sağlanamamakla birlikte, taleplerin araç kapasitesinden fazla olduğu durumlarda bir düğüme (müşteriye) birden fazla kez uğranılması gerekmektedir. Ayrıca, bazı problemlerde düğümlere (müşterilere) yapılan ziyaretlerin belirli zaman aralıklarında gerçekleştirilmesi gereken durumlar da söz konusu olabilmektedir. Bu kapsamda, ZPBD-ARP, ARP'nin bir varyasyonu olarak, her düğüme (müşteriye) birden fazla araç tarafından taşıma yapılabildiği, araç kapasitesinin dikkate alındığı ve zaman penceresi kısıtlarına sahip bir problem olarak tanımlanabilir. Bu problemde bazı düğümlerin talepleri araç kapasitesinden fazla olduğundan, birden fazla araç tarafindan bölünebilir teslimat yapılmaktadır. Talebin bölünebilir olması, araç kapasitesini aşan taleplere sahip müşterilere hizmet vermeyi mümkün kılmaktadır. Ayrıca bölünebilir talebin, toplam maliyeti azaltıcı yönde bir etkisi bulunabileceği öngörülmektedir (Belfiore ve diğ., 2008).

Bu çalışmada dikkate alınan ZPBD-ARP ile ilgili literatürde bulunan ilk çalışmalar Dror ve Trudeau (1989); Dror ve Trudeau (1990) tarafindan yapılmıştır. Bu çalışmalarda, talebin bölünebilir yapısını mümkün kılan bir matematiksel formülasyon geliştirilerek, bu yöntemin araç sayısı ve toplam kat edilen mesafe açısından ekonomikliği araştırılmıştır. Dror ve diğ. (1994) tarafından yapılan bir başka çalışmada ise bir tamsayılı programlama modeli geliştirilmiş, kısıtlar gruplandırılarak aralarındaki hiyerarşi belirlenmiş ve dal-sınır algoritması kullanılarak problemin çözümü sağlanmıştır. Frizzell ve Giffin (1992); Frizzell ve Giffin (1995) tarafından rotalama probleminin çözümü için ızgara ağ uzaklıkları kullanılarak, bir evrimsel meta-sezgisel algoritma geliştirilmiştir.

Geçmiş yıllarda ARP ile ilgili çok sayıda çalışma yapılmıştır. Bu konuda ilk çalışma Dantzig ve Ramser (1959) tarafından yapılmış, çalışmada doğrusal programlama modeli temelli bir çözüm yaklaşımı geliştirilmiştir. Lenstra ve Kan (1981) problemin karmaşıklığını analiz ederek ARP'nin NP-zor olduğunu göstermişlerdir. Solomon ve Desrosiers (1988)'e göre, ZPBD-ARP, ARP'nin bir uzantısı olduğu için bu problem de NP-zor olarak sınıflandırılabilir. Her ne kadar talebin bölünebilir yapısı problemin gevşetilmesi yönünden olumlu bir katkı sağlasa da, ZPBD-ARP problemi NP-zor olarak sınıflandırılmaktadır (Archetti ve diğ., 2005). $\mathrm{Bu}$ nedenle, problemin çözümü için çeşitli sezgisel veya meta-sezgisel çözüm yaklaşımları geliştirilmiştir (Solomon, 1987; Ho ve Haugland, 2004). 
Bu çalışmada, Cavdur ve diğ. (2016) tarafindan yapılan çalışmanın bir uzantısı olarak, afet sonrası ortaya çıkan geçici-afet-müdahale tesislerinden afetzedelere yardım malzemesi dağıtım problemi için bir çözüm yaklaşımı önerilmektedir. Ele alınan dağıtım problemi, ZPBD-ARP'ye dönüştürülerek, afetzedelere en az maliyet (uzaklık) ile taşıma yapılmasını sağlayan bir dağıtım ağı tasarlanmıştır. Bu sayede, afet sonrası ortaya çıkan karmaşadan en az şekilde etkilenerek, afetzedelerin ihtiyaç duydukları yardım malzemelerine en kısa mesafeden ulaşmaları amaçlanmıştır.

\section{METODOLOJI}

Bu çalışmada, Cavdur ve diğ. (2016) tarafindan geliştirilen modelin sonuçları kullanılarak, başlangıç dağıtım problemi, her biri ZPBD-ARP olarak çözülen daha küçük boyutlu altproblemlere ayrılmıştır. Ele alınan her bir alt problem, afetzedelere talepleri oranında ve en az maliyet (uzaklık) ile yardım malzemesinin taşınmasını amaçlayan bir araç rotalama problemi olarak tanımlanmaktadır.

Önerilen ZPBD-ARP yaklaşımı ile optimal çözümlerinden yararlanılan Cavdur ve diğ. (2016) tarafından geliştirilen model arasındaki ilişki Şekil 1'de gösterilmektedir. Geliştirilen model ile geçici tesislerin konumları, sayıları (yardım malzemesi stok bilgileri) ve afetzedelere dağıtılması gereken yardım malzemesi miktarları belirlenmektedir. Belirlenen optimal yardım malzemesi dağıtım miktarları $\left(x_{i j k}^{*}\right)$, tesislerden afetzedelere taşınması gereken miktarlar olarak değerlendirilmiş olup, bu değer ZPBD-ARP modelinin girdi parametresi (düğüm talebi $q_{i}$ ) olarak dikkate alınmıştır. Önerilen ZPBD-ARP modeli ile geçici-afet-müdahale-tesislerinde önceden konumlandırılan yeterli sayıda ve özdeş kapasiteye sahip araçlar için taşınacak yardım malzemesi miktarı ve çeşidi belirlenerek, bu araçlara en kısa rotaların ataması yapılmaktadır.

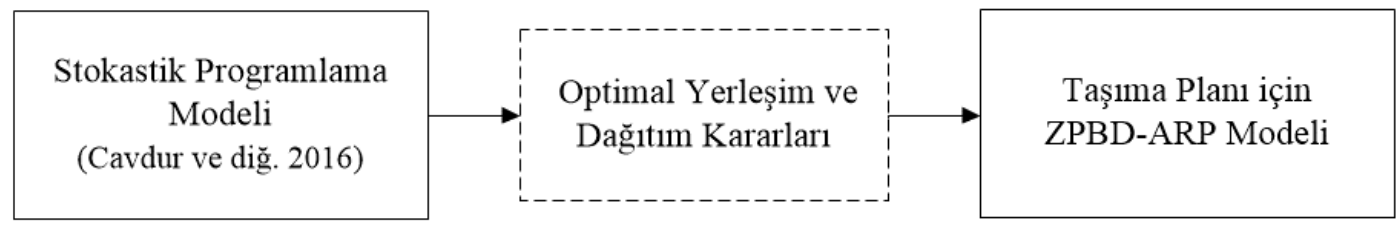

Şekil 1:

Önerilen Çözüm Yaklaşımı

Afet sonrası dağıtım probleminin ZPBD-ARP'ye uyarlanmasıyla oluşturulan matematiksel programlama modeli aşağıdaki gibidir:

Dizin kümeleri ve parametreler;

$N$ : düğ̈̈̈m say1s1

$K$ : araç sayısı

$i, j$ : düğümler $i, j=0, \ldots, N$

$k$ : araçlar $k=1, \ldots, K$

$a_{k}: k$. aracin kapasitesi $(k=1, \ldots, K)$

$d_{i j}: i$ ve $j$ dügümleri arasındaki maliyet (uzaklık) $(i, j=1, \ldots, N)$

$e_{i}: i$. düğüme en erken varış süresi $(i=1, \ldots, N)$

$l_{i}: i$. düğüme en geç varış süresi $(i=1, \ldots, N)$

$q_{i}: i$. düğümün yardım malzemesi talep miktarı $(i=1, \ldots, N)$

$s_{i}: i$. düğüme hizmet verme süresi $(i=1, \ldots, N)$

$t_{i j}: i$ ve $j$ düğümleri arasındaki taşıma süresi $(i, j=1, \ldots, N)$ 
Değişkenler;

$x_{i j k}=\left\{\begin{array}{cc}1, & \text { eğer } k . \text { araç } i . \text { düğümden } j . \text { düğüme gidiyorsa } \\ 0, & \text { aksi halde }\end{array}\right\}(i, j=1, \ldots, N, k=1, \ldots, K)$

$y_{i k}: i$. dügüme $k$. araç tarafından gönderilen miktarın talep miktarına oranı $(i=1, \ldots, N, k=$ $1, \ldots, K)$

$b_{i k}: i$. dügüme $k$. araç tarafından yapılan hizmetin başlangıç süresi $(i=1, \ldots, N)$

Amaç Fonksiyonu:

Kisitlar:

$$
\min z=\sum_{i=0}^{N} \sum_{j=0}^{N} \sum_{k=1}^{K} d_{i j} x_{i j k}
$$

$$
\begin{gathered}
\sum_{j=1}^{N} x_{0 j k}=1, \quad k=1, \ldots, K \\
\sum_{i=0}^{N} x_{i p k}-\sum_{j=0}^{N} x_{p j k}=0, \quad p=0, \ldots, N ; k=1, \ldots, K \\
\sum_{k=1}^{K} y_{i k}=1, \quad i=1, \ldots, N \\
\sum_{i=1}^{N} q_{i} y_{i k} \leq a_{k}, \quad k=1, \ldots, K \\
y_{i k} \leq \sum_{j=0}^{N} x_{j i k}, \quad i=1, \ldots, N ; k=1, \ldots, K \\
b_{i k}+s_{i}+t_{i j}-M_{i j}\left(1-x_{j i k}\right) \leq b_{j k}, \quad i=1, \ldots, N ; j=1, \ldots, N ; k=1, \ldots, K \\
e_{i} \leq b_{i k} \leq l_{i}, i=1, \ldots, N \\
i=1, \ldots, N ; k=1, \ldots, K \\
y_{i k} \geq 0, \quad \begin{array}{r}
i=1, \ldots, N ; k=1, \ldots, K \\
b_{i k} \geq 0, \\
x_{j i k} \in\{0,1\}, \quad k, j=0, \ldots, N ; k=1, \ldots, K \\
i=0, \ldots, N
\end{array}
\end{gathered}
$$

Denklem (1)'de verilen modelin amaç fonksiyonu, toplam mesafenin en küçüklenmesinden oluşmaktadır. Belirtilen bu amaç fonksiyonu ile afetzedelere en az maliyet (uzaklık) ile yardım malzemesi dağıtımının yapılması sağlanmaktadır. Denklem (2)'de belirtilen kısıt ile her aracın depo düğümünden çıkışı sağlanmaktadır. Denklem (3) akış dengesi kısıtı olup, ayrıca her aracın tüm düğümlere uğradıktan sonra depoya dönüşünü sağlamaktadır. Denklem (4) talep karşılama 
kısıtı olarak tanımlanarak, tüm talebin karşılanmasını garanti etmektedir. Denklem (5), araç kapasite kısıtı olarak temsil edilmiş olup, Denklem (6) değişkenler arası ilişkiyi yansıtmaktadır. Denklem (7) ve Denklem (8), zaman penceresi kısıtları olarak belirlenmiştir. Aynı zamanda bu denklemler, alt tur oluşumunu engelleyen kısıtlardır (sub-tour elimination constraints). $M_{i j}$ yeterince büyük bir sayı olmak üzere; $M_{i j}=l_{i}+t_{i j}-e_{j}$ eşitliği ile elde edilebilir. Denklem (9), Denklem (10) ve Denklem (11) değişken tanımlamalarının yapıldığı kısıtlar olarak belirtilmiştir.

\section{UYGULAMA VE SONUÇLAR}

Bu çalışmada önerilen ZBD-ARP yaklaşımı ile, Cavdur ve diğ. (2016) tarafından geliştirilen modelin sonuçları dikkate alınarak, geçici-afet-müdahale tesislerinden afetzedelere yardım malzemelerinin en az maliyet ile (uzaklık) taşınması sağlanmıştır (Cavdur ve diğ. (2016) tarafından geliştirilen modelin detayları Ek 1'de sunulmuştur). Önerilen yaklaşımın uygulanabilirliğinin test edilmesi amacıyla, AFAD-Deprem Dairesi Başkanlığ oluşturulan, Bursa ili deprem örnek olayı verilerinden yararlanılmıştır. Bu örnek olay, Aralık ayında meydana gelen ve şiddeti 7,0 olan bir deprem olarak belirlenmiş ve Bursa iline bağlı ilçelerde bu depremden etkilenecek afetzede sayısı tahmin edilmiştir. Çalışmada uygulama alanı olarak ele alınan ve 64 mahallesi bulunan Yıldırım ilçesinde tahmini afetzede sayısı 623.999 olarak belirtilmiştir. Bu bilgiler doğrultusunda, deprem örnek olayı verileri baz alınarak, geçiciafet müdahale tesis yerleşimi problemi çözülmüştür (Cavdur ve diğ., 2016).

ZPBD-ARP modelinde, Cavdur ve diğ. (2016) tarafından geliştirilen model sonucu oluşturulan her deprem senaryosu için elde edilen deterministik çözümleri sonucu ortaya çıkan birbirinden bağımsız alt-taşıma problemleri dikkate alınmıştır. Şekil 2'de Cavdur ve diğ. (2016) tarafindan geliştirilen modelin en kötü durum senaryosunun (worst case) deterministik çözümü şebeke gösterimi ve ZPBD-ARP'nin uygulanacağı alt-problem gösterilmektedir. Ele alınan en kötü durum senaryosunda dokuz alt-taşıma problemi ortaya çıkarılmış ve bu alt-taşıma problemlerinde, geçici-afet müdahale tesislerinin açıldığı düğümler depo dügüüünü (beyaz renk), bu tesislerden yardım malzemelerinin akışının yapıldığı diğer düğümler ise talep (afetzede) düğümlerini (gri renk) göstermektedir. Oluşturulan alt-problemlere ait şebeke büyüklükleri Tablo 1'de gösterilmiş̧ir. İki düğümden oluşan alt problemler için rotalama ihtiyacı bulunmadığından, bu çalışmada, şebeke büyüklüğü en az üç düğümden oluşan altproblemler dikkate alınmıştır. Örneğin; Alt Problem-1'de 4 numaralı düğümde gösterilen mahallede bulunan geçici-afet-müdahale tesisinden, 3, 8, 17, 19, 20, 23, 36, 47 ve 59 numaralı dügümlerle gösterilen mahallerde bulunan afetzedelere yardım malzemesi dağıtımı yapılmaktadır. Dolayısıyla, önerilen ZPBD-ARP modelinde, 4 numaralı dügüm depo düğümünü, 3, 8, 17, 19, 20, 23, 36, 47 ve 59 numaralı düğümler ise talep düğümlerini temsil etmektedir. Yardım malzemesi talepleri yine, Cavdur ve diğ. (2016) tarafından geliştirilen model sonucu elde edilen optimal dağıtım miktarları $\left(x_{i j k}^{*}\right)$ olarak ZPBD-ARP modelinin girdi parametresini oluşturmaktadır.

Çalışmada, tüm mahalleler arası uzaklıklar ve malzeme taşıma süreleri belirlenmiş olup, depo düğümlerde konumlandırılmış ve kapasiteleri 120.000 litre olan 20 özdeş araç kullanıldığ1 varsayılmıştır. Afetzedelere dağıtımı yapılacak malzemelerin su, gıda kiti ve hijyenik kit olmak üzere üç tip olduğu varsayılmış ve bu malzemelere ait birim hacim bilgileri, ZPBD-ARP modelinde girdi parametreleri olarak dikkate alınmıştır. Ayrıca tüm talep dügümlerinin bir günlük zaman penceresine sahip olduğu varsayılmıştır. 


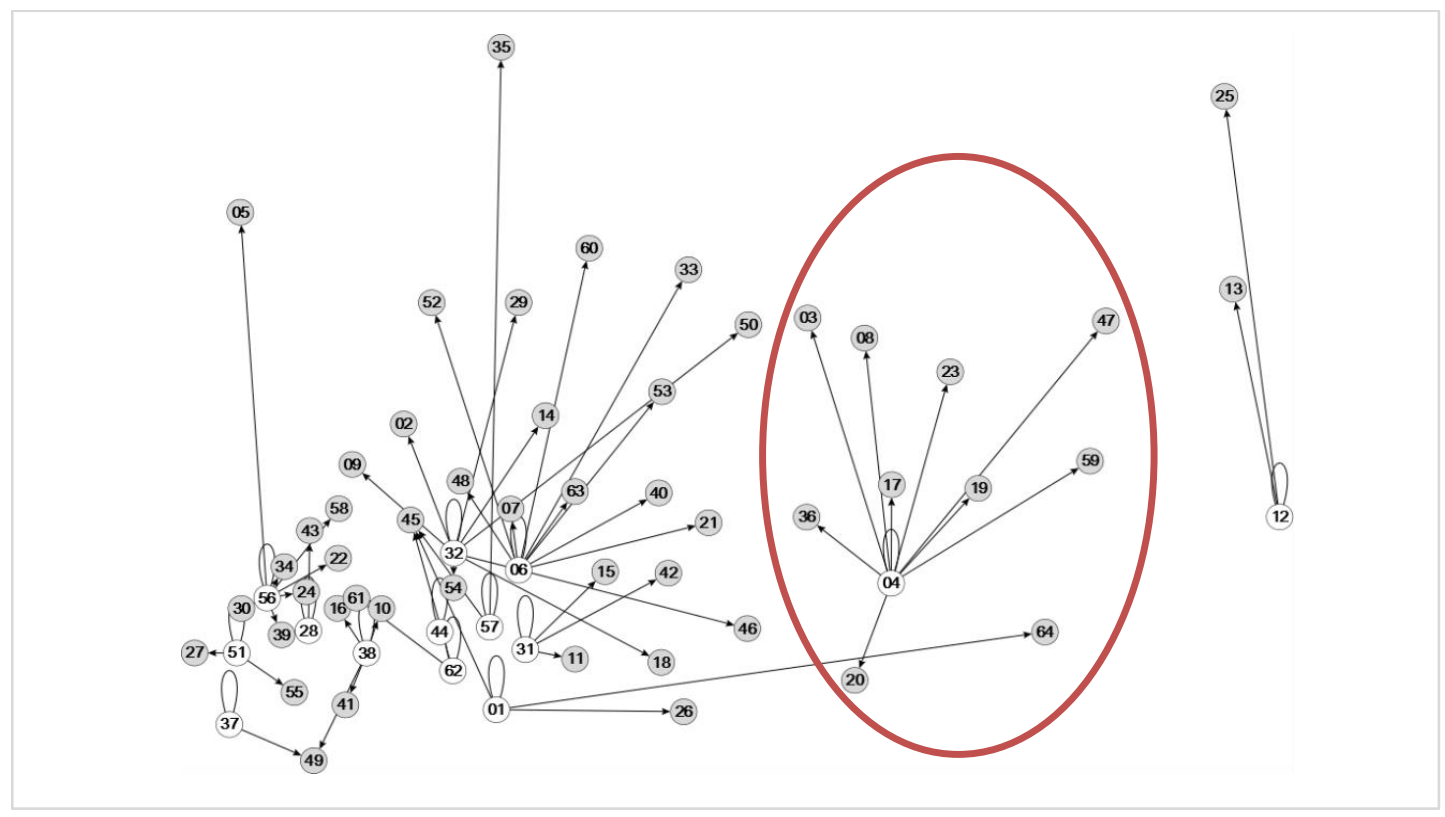

Şekil 2:

Cavdur ve diğ. (2016) tarafindan geliştirilen model sonuçlarının şebeke gösterimi ve alt taşıma problemleri

Tablo 1. Alt taşıma problemlerinin şebeke büyüklükleri

\begin{tabular}{|l|c|c|c|c|c|c|c|c|c|}
\hline $\begin{array}{l}\text { Alt } \\
\text { problem }\end{array}$ & 1 & 2 & 3 & 4 & 5 & 6 & 7 & 8 & 9 \\
\hline $\begin{array}{l}\text { Ağ } \\
\text { büyüklüğü }\end{array}$ & 10 & 4 & 10 & 3 & 4 & 9 & 4 & 3 & 8 \\
\hline
\end{tabular}

$\mathrm{Bu}$ bilgiler 1şı̆̆ında, ZPBD-ARP modeli Mathematical Programming Language (MPL) ortamında kodlanmış ve Gurobi çözücüsü kullanılmıştır. Çözümler, Intel Core i5 CPU 2450 2,50GHz hızında işlemciye, 8GB RAM ara belleğe sahip kişisel bir bilgisayarın kullanımıyla elde edilmiştir. Alt Problem-1'in çözüm süresi 6,11 saniye olup, sonuçlar Tablo 2'de gösterilmiştir. Diğer alt problem sonuçları ve çözüm sürelerine ilişkin bilgiler Ek 2'de verilmiştir. Tabloda, her araç için model sonucunda ortaya çıkan en kısa rotalar ve bu rotalar üzerinde yapılan yardım malzemesi dağıtım miktarları (parantez içinde) gösterilmiştir. Çalışma kapsamında en kötü deprem senaryosu baz alınarak, oluşabilecek maksimum talebi karşılayacak şekilde bir rotalama yapılmış olup, daha iyimser senaryolar (deprem şiddetinin daha hafif derecede olduğu) altında taleplerin ve araç sayılarının azalacağı öngörülmektedir.

Alt Problem-1 için ZPBD-ARP modeli çözümünün şebeke gösterimi, düğümlerin yaklaşık koordinatları dikkate alınarak Şekil 3'te verilmiştir. Şekilde, sonuçları gösterilen Alt Problem-1 için (Şekil 2), 4 numaralı depo düğümünün hizmet verdiği dokuz düğüme hangi araçlarla ve hangi rotalar üzerinden taşıma yapıldığ 1 gösterilmiştir. Örneğin, 1, 3, 4 ve 18 numaralı araçların $(4-59-23-4)$ rotasını izledikleri görülmektedir. Şeklin okunabilirliğini sağlamak amacıyla depoya dönüşlere ilişkin bağlantılar şekil üzerinde gösterilmemiştir. 
Tablo 2. Alt problem-1 sonuçları: rotalar ve taşıma miktarları

\begin{tabular}{|c|c|}
\hline Araç & Taşıma Planı \\
\hline 1 & $4-59(47.617)-23(69.720)-4$ \\
\hline 2 & $4-3(108.211)-4$ \\
\hline 3 & $4-59(47.617)-23(69.720)-4$ \\
\hline 4 & $4-59(47.617)-23(69.720)-4$ \\
\hline 5 & $4-3(108.211)-4$ \\
\hline 6 & $4-20(26.255)-17(81.676)-4$ \\
\hline 7 & $4-19(83.520)-20(36.456)-4$ \\
\hline 8 & $4-19(120.000)-4$ \\
\hline 9 & $4-47(119.870)-4$ \\
\hline 10 & $4-47(119.870)-4$ \\
\hline 11 & $4-19(98.953)-20(20.903)-4$ \\
\hline 12 & $4-3(108.211)-4$ \\
\hline 13 & $4-17(119.993)-4$ \\
\hline 14 & $4-8(120.000)-4$ \\
\hline 15 & $4-3(108.211)-4$ \\
\hline 16 & $4-8(62.191)-36(53.208)-4$ \\
\hline 17 & $4-36(106.417)-4$ \\
\hline 18 & $4-59(47.617)-23(69.720)-4$ \\
\hline 19 & $4-36(53.208)-8(60.733)-4$ \\
\hline 20 & $4-47(108.371)-4$ \\
\hline
\end{tabular}

Önerilen ZPBD-ARP modeli ile tüm alt problemlerin çözümleri sağlanmış ve her alt problem için gereken araç sayısı ve bu araçların ortalama doluluk oranları Tablo 3'te gösterilmiştir. Tabloda görüldüğü gibi, en kötü deprem senaryosuna karşıllk gelen yardım malzemesi talepleri yüksek olduğundan, bu durumun genel olarak araç doluluk oranlarına yansıdığı gözlenmektedir. Tablodan ve şebeke gösterimlerinden de anlaşılacağı üzere, şebeke büyüklüğü arttıkça, araç doluluk oranlarında genel olarak bir artış gözlenmektedir. Buna karşın, şebeke büyüklüğü daha az olan alt problemlerde araç doluluk oranının nispeten azaldığı görülmektedir. Ayrıca, tek aracın kullanıldığı alt problemlerde çoğunlukla rota uzunluğu ve süresi diğer alt problemlere oranla daha yüksek olduğu görülmektedir. 


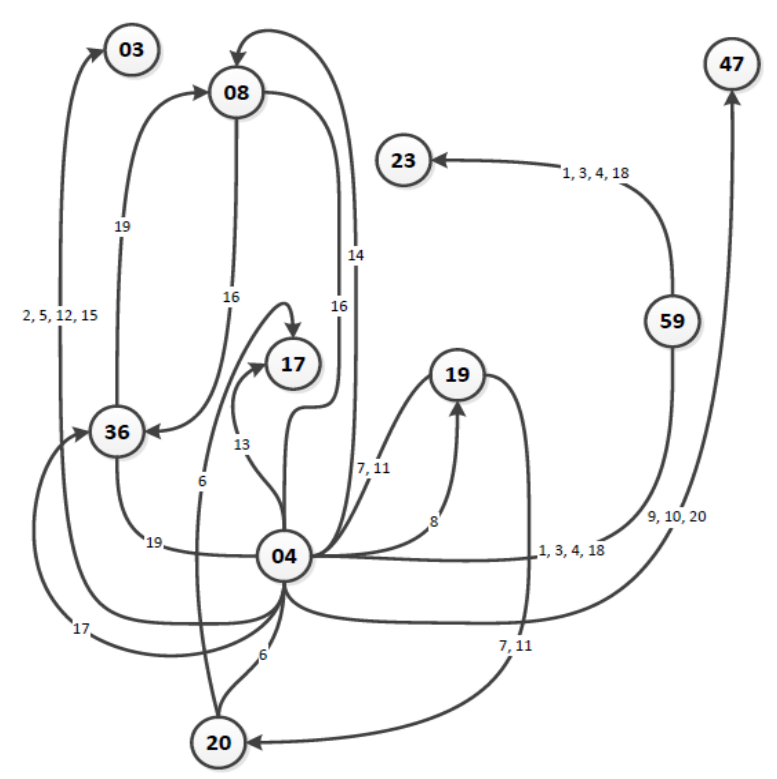

Şekil 3:

Alt problem-1 çözümü şebeke gösterimi

\section{TARTIŞMA}

$\mathrm{Bu}$ çalışmada, afet durumlarında oluşan yardım malzemesi dağıtım problemi, ZPBD-ARP olarak modellenmiş ve Cavdur ve diğ. (2016) tarafından geliştirilen modelin sonuçları kullanılarak ZPBD-ARP olarak çözülen daha küçük boyutlu alt-taşıma problemlerine dönüştürülmüştür.

Tablo 3. Alt problemlerin sonuçları

\begin{tabular}{|l|c|c|c|c|}
\hline $\begin{array}{l}\text { Alt } \\
\text { Problem }\end{array}$ & Ağ büyüklüğü & $\begin{array}{c}\text { Kullanılan Araç } \\
\text { Sayıs }\end{array}$ & $\begin{array}{c}\text { Ortalama Araç } \\
\text { Doluluğu }\end{array}$ & $\begin{array}{c}\text { Maksimum Rota } \\
\text { Uzunluğu ve } \\
\text { Süresi (km-min) }\end{array}$ \\
\hline 1 & 10 & 20 & $\% 96$ & $8,8-10,6$ \\
\hline 2 & 4 & 1 & $\% 71$ & $18,7-22,4$ \\
\hline 3 & 10 & 14 & $\% 99$ & $9,2-11,04$ \\
\hline 4 & 3 & 1 & $\% 45$ & $9,9-11,9$ \\
\hline 5 & 4 & 6 & $\% 95$ & $4,0-4,0$ \\
\hline 6 & 9 & 8 & $\% 93$ & $11,0-12,2$ \\
\hline 7 & 4 & 3 & $\% 98$ & $4,0-4,1$ \\
\hline 8 & 3 & 2 & $\% 52$ & $2,0-1,9$ \\
\hline 9 & 8 & 4 & $\% 97$ & $12,0-13,9$ \\
\hline
\end{tabular}

Çalışmada, Cavdur ve diğ. (2016) tarafından geliştirilen model ile belirlenen optimal yardım malzemesi dağıtım miktarları $\left(x_{i j k}^{*}\right)$, tesislerden afetzedelere taşınması gereken miktarlar olarak değerlendirilmiş olup, bu değer ZPBD-ARP modelinin girdi parametresi olarak $\left(q_{i}\right)$ dikkate alınmıştır. Önerilen ZPBD-ARP modeli ile afet sonrası, yardım malzemelerinin depolandıkları tesislerden afetzedelere uygun araçlarla, hangi rotalar üzerinden taşıma yapacağına karar veren bir taşıma planı oluşturulmuştur. Ayrıca, ZPBD-ARP modeli ile geçici-afet-müdahale- 
tesislerinde önceden konumlandırılan yeterli sayıda ve özdeş kapasiteye sahip araçlar için taşınacak yardım malzemesi miktarı ve çeşidi belirlenerek, bu araçlara en kısa rotaların ataması yapılmaktadır.

Çalışmada, önerilen yaklaşımın uygulanması amacıyla, Bursa ili deprem örnek olayı verileri baz alınarak afet sonrası ortaya çıkan yardım malzemesi dağıtım probleminin çözümü sağlanmıştır. ZPBD-ARP modelinde, Cavdur ve dĭ̆ . (2016) tarafından geliştirilen modelin her deprem senaryosunun deterministik çözümleri sonucu ortaya çıkan alt taşıma problemleri dikkate alınmıştır. Problem boyutundaki küçülmenin çözüm süresi açısından katkılar sağladığı, geliştirilen örnek olay kullanılarak oluşturulan her bir alt-problemin kişisel bir bilgisayarda saniyeler içinde çözülebildiği görülmektedir.

Gelecek çalışmalarda, afet sonrası ortaya çıkan yardım malzemesi dağıtım problemi için daha bütünsel bir şekilde; yerleşim, dağıtım ve taşıma kararlarının birlikte dikkate alındığı çözüm yaklaşımları geliştirilebilir. Ayrıca, taşıma planı için önerilen araç rotalama problemi, iki-aşamalı stokastik programlama modeline entegre edilerek, modelin kapsamı genişletilebilir. $\mathrm{Bu}$ durumlarda, problem karmaşıklığ 1 ve boyutundaki artış nedeniyle çözüm için bir takım sezgisel veya meta-sezgisel yöntemlere başvurulması gerekebilir. Bir diğer gelecek çalışma konusu ise, araçlar tarafından yardım malzemelerinin taşınması sırasında, yolların yıkılma veya kullanılamama durumlarının dikkate alınması ile rotalamanın yapılması olabilir. Böyle bir çalışmada ise, çeşitli deprem senaryoları geliştirilerek, problemin çözümünün sağlanması gerekmektedir.

\section{TEŞEKKÜR}

Bu çalışma, Türkiye Bilimsel ve Teknolojik Araştırma Kurumu (TÜBİTAK) tarafindan 115M020 numaralı proje kapsamında desteklenmiştir.

\section{KAYNAKLAR}

1. Adıvar, B. ve Mert, A. (2010) International disaster relief planning with fuzzy credibility, Fuzzy Optimization and Decision Making, 9(4), 413-433. doi:10.1007/s10700-010-9088-8

2. Afshar, A., Rasekh, A. ve Afshar, M.H. (2009) Risk-based optimization of large flooddiversion systems using genetic algorithms, Engineering Optimization, 41(3), 259-273. doi:10.1080/03052150802433213

3. Altay, N. ve Green, W.G. (2006) OR/MS research in disaster operations management, European Journal of Operational Research, 175(1), 475-493. doi:10.1016/j.ejor.2005.05.016

4. Archetti, C., Mansini, M. ve Speranza, M.G. (2005) Complexity and Reducibility of the Skip Delivery Problem, Transportation Science, 39(2), 182-187. doi:10.1287/trsc.22.1.1

5. Barbarosoğlu, G. ve Arda, Y. (2004) A two-stage stochastic programming framework for transportation planning in disaster response, Journal of the Operational Research Society, 55(1), 43-53. doi:10.1057/palgrave.jors.2601652

6. Beamon, B., M. ve Balcik, B. (2008) Performance measurement in humanitarian relief chains, International Journal of Public Sector Management, 21(1), 4-25. doi:10.1080/13675560701561789

7. Belfiore, P., Tsugunobu, H. ve Yoshizaki, Y. (2008) Scatter search for vehicle routing problem with time windows and split deliveries, Vehicle Routing Problem, 1-14. 
8. Ben-Tal, A., Chung, B.D., Mandala, S.R. ve Yao, T. (2011) Robust optimization for emergency logistics planning: Risk mitigation in humanitarian relief supply chains, Transportation Research Part B, 45(8), 1177-1189. doi.org/10.1016/j.trb.2010.09.002

9. Chan, Y., Carter, W.B. ve Burnes, M.D. (2001) A multiple-depot, multiple-vehicle, location routing problem with stochastically processed demands, Computers \& Operations Research, 28(8), 803-826. doi:10.1016/S0305-0548(00)00009-5

10. Cavdur, F., Kose-Kucuk, M. ve Sebatli, A. (2016) Allocation of temporary disaster response facilities under demand uncertainty: An earthquake case study, International Journal of Disaster Risk Reduction, 19, 159-166. doi:10.1016/j.ijdrr.2016.08.009

11. Dantzig, G.B. ve Ramser, J.H. (1959) The truck dispatching problem, Management Science, 6(1), 80-91. doi.org/10.1287/mnsc.6.1.80

12. Dror, M. ve Trudeau, P. (1989) Savings by Split Delivery Routing, Transportation Science, 23(2), 141-145. doi.org/10.1287/trsc.23.2.141

13. Dror, M. ve Trudeau, P. (1990) Split Delivery Routing, Naval Research Logistics, 37(3), 383-402. doi:10.1002/nav.3800370304

14. Dror, M., Laporte, G. ve Trudeau, P. (1994) Vehicle routing with split deliveries, Discrete Applied Mathematics, 50(3), 239-254. doi:10.1016/0166-218X(92)00172-I

15. Erdik, M., Erkin, E. ve Yeğin, M. (2003) Planlama Sürecinde Yönetmeliklerin Afetler Açısından Etkin Hâle Getirilmesi, Kocaeli Deprem Sempozyumu, 334.

16. Frizzell, P.W. ve Giffin, J.W. (1992) The bounded split delivery vehicle routing problem with grid network distances, Asia Pacific Journal of Operational Research, 9(1), 101-116. doi:A1992KP79100008

17. Frizzell, P.W. ve Giffin, J.W. (1995) The Split Delivery Vehicle Scheduling Problem with Time Windows and Grid Network Distances, Computers \& Operations Research, 22(6), 655-667. doi:10.1016/0305-0548(94)00040-F

18. Galindo, G. ve Batta, R. (2013) Review of recent developments in OR/MS research in disaster operations management, European Journal of Operational Research, 230(2), 201211. doi:10.1016/j.ejor.2013.01.039

19. Genç, F.N. (2007) Türkiye'de doğal afetler ve doğal afetlerde risk yönetimi, Stratejik Araştırmalar Dergisi, 9(5), 201-226.

20. Haghani, A. ve Oh, S. (1996) Formulation and solution of a multi-commodity, multi-modal network flow model for disaster relief operations, Transportation Research Part A, 30(3), 231-250. doi:10.1016/0965-8564(95)00020-8

21. Ho, S.C. ve Haugland, D. (2004) A tabu search heuristic for the vehicle routing problem with time windows and split deliveries, Computers \& Operations Research, 31 (12), 1947 1964, 2004. doi.org/10.1016/S0305-0548(03)00155-2

22. https://aats.afad.gov.tr/sozluk4.php, Erişim Tarihi: 23.11.2017, Konu: T.C. Başbakanlık Afet ve Acil Durum Yönetimi Başkanlığı Açıklamalı Afet Yönetimi Terimleri Sözlüğü.

23. Lenstra, J.K. ve Kan, A.H.G. (1981) Complexity of Vehicle and Scheduling Problems, Networks, 11(2), 221-227. doi:10.1002/net.3230110211

24. Mete, H.O ve Zabinsky, Z.B. (2010) Stochastic optimization of medical supply location and distribution in disaster management, International Journal of Production Economics, 126(1), 76-84. doi:10.1016/j.ijpe.2009.10.004 
25. Nagurney, A., Yu, M. ve Qiang, Q. (2011) Supply chain network design for critical needs with outsourcing, Papers in Regional Science, 90(1), 123-142. doi:10.1111/j.14355957.2010.00317

26. Natarajarathinam, M., Capar, I. ve Narayanan, A. (2009) Managing supply chains in times of crisis: a review of literature and insights, International Journal of Physical Distribution and Logistic Management, 39(7), 535-573. doi:10.1108/09600030910996251

27. Nolz, P.C., Semet, F. ve Doerner, K.F. (2011) Risk approaches for delivering disaster relief supplies, OR Spectrum, 33(3), 543-569. doi:10.1007/s00291-011-0258-z

28. Özdamar, L., Ekinci, E. ve Küçükyazıc1, B. (2004) Emergency Logistics Planning in Natural Disasters, Annals of Operations Research, 129(1), 217-245. doi:10.1023/B:ANOR.0000030690.27939.39

29. Özdamar, L.ve Demir, O. (2012) A hierarchical clustering and routing procedure for large scale disaster relief logistics planning, Transportaion Research Part E, 48(3), 591-602. doi.org/10.1016/j.tre.2011.11.003

30. Rawls, C.G. ve Turnquist, M.A. (2010) Pre-positioning of emergency supplies for disaster response, Transportation Research Part B, 44(4), 521-34. doi:/10.1016/j.trb.2009.08.003

31. Salman, F.S. ve Gül, S. (2014) Deployment of field hospitals in mass casualty incidents, Computers \& Industrial Engineering, 74, 37-51. doi:10.1016/j.cie.2014.04.020

32. Sheu, J.B. (2010) Dynamic relief-demand management for emergency logistics operations under large-scale disasters, Transportation Research Part E, 46(1), 1-17. doi:10.1016/j.tre.2009.07.005

33. Solomon, M.M. (1987) Algorithms for the vehicle routing and scheduling problems with time windows constraints, Operations Research, 35(2), 254-265. doi:10.1287/opre.35.2.254

34. Solomon, M.M. ve Desrosiers, J. (1988) Survey paper-time window constrained routing and scheduling problems, Transportation Science, 22(1), 1-13. doi:10.1287/trsc.22.1.1

35. Song, R., He S. ve Zhang, L. (2009) Optimum transit operations during the emergency evacuations, Journal of Transportation Systems Engineering and Information Technology, 9(6), 154-160. doi.org/10.1016/S1570-6672(08)60096-3

36. Vitoriano, B., Ortuno, M.T., Tirado, G. ve Montero, J. (2011) A multi-criteria optimization model for humanitarian aid distribution, Journal of Global Optimization, 51(2), 189-208. doi.org/10.1007/s10898-010-9603-z

37. Yi, W. ve Özdamar L. (2007) A dynamic logistics coordination model for evacuation and support in disaster response activities, European Journal of Operational Research, 179(3), 1177-1193. doi:10.1016/j.ejor.2005.03.07 


\section{Ek 1. İki-Aşamalı Stokastik Programlama Modeli}

Dizin kümeleri ve parametreler;

$i: \quad$ mahalle indisi, $i=1 \ldots n_{N}$

$j: \quad$ mahalle indisi, $j=1 \ldots n_{N}$

$k: \quad$ temel ihtiyaç malzeme tipi, $k=1 . . n_{C}$

$\xi: \quad$ senaryo indisi

$d_{j k}^{\xi}: \quad \xi$. senaryoda $j$. mahallenin $k$ tipi temel ihtiyaç malzeme talep miktarı

$c_{i j}: \quad i$ ve $j$ mahalleri arasındaki gerçek uzaklık $(\mathrm{km})$

$v_{k}: \quad k$ tipi temel ihtiyaç malzemesinin birim hacmi (lt)

$w_{k}: \quad k$ tipi temel ihtiyaç malzemesinin birim ağırlı̆ $\breve{g}_{1}(\mathrm{~kg})$

$V: \quad$ geçici-afet-müdahale tesisi birim hacim kapasitesi (lt)

$W: \quad$ geçici-afet-müdahale tesisi birim ağırlık kapasitesi $(\mathrm{kg})$

$R_{k_{p} k_{q}}: k_{p}$ ve $k_{q}$ temel ihtiyaç malzemeleri arasındaki tedarik oranı $k_{p}, k_{q} \in k$

$N_{i}$ : $\quad i$. mahallede açılabilecek maksimum geçici-afet-müdahale tesisi sayısı

$N_{T}: \quad$ toplam açılabilecek geçici-afet-müdahale tesisi sayısı

$S_{i}: \quad i$. mahallenin güvenlik düzeyi

$T_{S}: \quad$ sağlanması gereken minimum güvenlik düzeyi eşik değeri

$\alpha: \quad$ hizmet verilen mahalle sayısı üst limiti

$\beta$ : $\quad$ hizmet alınan mahalle sayısı üst limiti

$\lambda: \quad$ ölçek faktörü

$\gamma: \quad$ karşılanamayan birim maliyet talebi

$p_{\xi:} \quad \xi$. senaryonun olasilık değeri

Değişkenler;

$z_{i:} \quad i$. mahallede kurulan geçici-afet-müdahale tesis sayıs1

$x_{i j k}^{\xi}: \xi$. senaryoda $i$. mahallede kurulan geçici-afet-müdahale tesisinden $j$. mahalleye gönderilen $k$ tipi temel ihtiyaç malzeme miktarı

$u_{j k}^{\xi}: \quad \xi$. senaryoda $j$. mahallede $k$ tipi temel ihtiyaç malzemesinin karşılanamayan talep miktar1

$$
y_{i j}^{\xi}=\left\{\begin{array}{cc}
1, & i . \text { mahallede kurulan geçici tesis } j . \text { mahalleye hizmet veriyorsa } \\
0, & \text { aksi takdirde }
\end{array}\right\}
$$

Amaç Fonksiyonu:

$$
\min z=\lambda\left(\sum_{i=1}^{n_{N}} z_{i}\right)+\sum_{\xi} p_{\xi}\left[\sum_{i=1}^{n_{N}} \sum_{j=1}^{n_{N}}\left(c_{i j}\left[\sum_{k=1}^{n_{C}} x_{i j k}^{\xi}\right]\right)+\sum_{j=1}^{n_{N}} \sum_{k=1}^{n_{C}} \gamma u_{j k}^{\xi}\right]
$$

Kisitlar:

$$
\begin{gathered}
\sum_{i=1}^{n_{N}} x_{i j k}^{\xi}=d_{j k}^{\xi}-u_{j k}^{\xi}, \quad \forall j, k, \xi \\
R_{k_{p} k_{q}} x_{i j k_{p}}^{\xi}=R_{k_{q} k_{p}} x_{i j k_{q^{\prime}}}^{\xi} \quad \forall i, j, k_{p}, k_{q} \in k, \forall \xi
\end{gathered}
$$


Köse Küçük M.,Çavdur F..: Zamn Pencr. Bölünmş Dağıtmlı Ar. Rot. Af. Sonr. Yrd. Mal. Dağ.Plan.

$$
\begin{aligned}
& \sum_{j=1}^{n_{N}} \sum_{k=1}^{n_{C}} v_{k} x_{i j k}^{\xi} \leq V z_{i}, \quad \forall i, \xi \\
& \sum_{j=1}^{n_{N}} \sum_{k=1}^{n_{C}} w_{k} x_{i j k}^{\xi} \leq W z_{i}, \quad \forall i, \xi \\
& z_{i} \leq\left(\sum_{j=1}^{n_{N}} \sum_{k=1}^{n_{C}} x_{i j k}^{\xi}\right), \quad \forall i, \xi \\
& \sum_{i=1}^{n_{N}} y_{i j}^{\xi} \leq \alpha, \quad \forall j, \xi \\
& \sum_{j=1}^{n_{N}} y_{i j}^{\xi} \leq \beta, \quad \forall i, \xi \\
& \sum_{k=1}^{n_{C}} x_{i j k}^{\xi} \leq M y_{i j}^{\xi}, \quad \forall i, j, \xi \\
& y_{i j}^{\xi} \leq \sum_{k=1}^{n_{C}} x_{i j k}^{\xi}, \quad \forall i, j, \xi \\
& z_{i} \leq N_{i}, \quad \forall i \\
& \sum_{i=1}^{n_{N}} z_{i} \leq N_{T} \\
& z_{i}=0 ; \exists i \in\left\{i: S_{i} \leq T_{S}\right\} \\
& z_{i} \in \mathbb{Z}^{+} \cup\{0\}, \quad \forall i \\
& x_{i j k}^{\xi} \in \mathbb{Z}^{+} \cup\{0\}, \quad \forall i, j, k, \xi \\
& u_{j k}^{\xi} \in \mathbb{Z}^{+} \cup\{0\}, \quad \forall j, k, \xi
\end{aligned}
$$




$$
y_{i j}^{\xi} \in\{0,1\}, \quad \forall i, j, \xi
$$

Denklem (1.1)'de verilen modelin amaç fonksiyonu; toplam açılan geçici-afet-müdahale tesis sayısı ile ikinci aşama amaç fonksiyonunun beklenen değerinin minimizasyonundan oluşmaktadır. İkinci aşamada amaç fonksiyonu, toplam uzaklık ağırlıklı temel ihtiyaç malzemesi miktarı ile karşılanamayan talebin minimizasyonundan oluşmaktadır. Denklem (1.2)'de verilen kısıt, temel ihtiyaç malzemesi talebinin geçici-afet-müdahale tesisinden karşılanacağı ve karşılanamayan talep miktarını göstermektedir. Denklem (1.3)'de belirtilen kısıt ile temel ihtiyaç malzemeleri arasındaki tedarik oranı sağlanmaktadır. Afetzedelerin geçiciafet-müdahale tesislerinde depolanan temel ihtiyaç malzemelerinden ihtiyaçları oranında faydalanması săglanmaktadır. Denklem (1.4) ve denklem (1.5)'de verilen kısıtlar, geçici-afetmüdahale tesisi için hacim ve ağırlık kapasite kısıtlarıdır. Denklem (1.6)'da belirtilen kısıt, değişkenler arasındaki ilişkiyi sağlayan kısıtdır. Denklem (1.7) ve denklem (1.8)'de belirtilen kısıtlar, afet sonrası kaos ve karmaşa ortamını önlemek amacıyla oluşturulan, hizmet alınacak geçici-afet-müdahale tesisi sayısı üst limiti ve hizmet verilecek mahalle sayısı üst limiti kısıtlarıdır. Denklem (1.9) ve denklem (1.10)'da verilen kısıtlar, değişkenler arasındaki mantıksal ilişkiyi sağlayan kısıtlardır. Denklem (1.11)'de belirtilen kısıt, her mahalle için açılabilecek maksimum geçici-afet-müdahale tesis sayısını göstermektedir. Denklem (1.12)'de belirtilen kısıt, maksimum açılabilecek geçici-afet-müdahale tesis sayısını göstermektedir. Denklem (1.13)'de belirtilen kısıt, belirlenen güvenlik düzeyinin altında güvenlik düzeyine sahip mahallere geçici-afet-müdahale tesisi açılmasını önleyen kısıtdır. (1.14), (1.15), (1.16) ve (1.17) numaralı denklemlerde belirtilen kısıtlar, değişken tanımlamalarının yapıldığı kısıtlardır. 
Köse Küçük M.,Çavdur F..: Zamn Pencr. Bölünmş Dağıtmlı Ar. Rot. Af. Sonr. Yrd. Mal. Dağ.Plan.

Ek 2. Alt problem sonuçları: rotalar ve taşıma miktarları

\begin{tabular}{|c|c|c|c|}
\hline Alt Problem & Araç & Rota ve Taşıma Miktarları & $\begin{array}{l}\text { Çözüm } \\
\text { Süresi } \\
\text { (s.) }\end{array}$ \\
\hline Alt Problem-1 & 1.1 & $\begin{array}{c}4-59(47.617)-23 \\
(69.720)-4 \\
\end{array}$ & \multirow{20}{*}{6,11} \\
\hline Alt Problem-1 & 1.2 & $4-3(108.211)-4$ & \\
\hline Alt Problem-1 & 1.3 & $\begin{array}{c}4-59(47.617)-23(69.720) \\
-4\end{array}$ & \\
\hline Alt Problem-1 & 1.4 & $\begin{array}{c}4-59(47.617)-23(69.720) \\
-4\end{array}$ & \\
\hline Alt Problem-1 & 1.5 & $4-3(108.211)-4$ & \\
\hline Alt Problem-1 & 1.6 & $\begin{array}{c}4-20(26.255)-17(81.676) \\
-4\end{array}$ & \\
\hline Alt Problem-1 & 1.7 & $\begin{array}{c}4-19(83.520)-20(36.456) \\
-4\end{array}$ & \\
\hline Alt Problem-1 & 1.8 & $4-19(120.000)-4$ & \\
\hline Alt Problem-1 & 1.9 & $4-47(119.870)-4$ & \\
\hline Alt Problem-1 & 1.10 & $4-47(119.870)-4$ & \\
\hline Alt Problem-1 & 1.11 & $\begin{array}{c}4-19(98.953)-20(20.903) \\
-4\end{array}$ & \\
\hline Alt Problem-1 & 1.12 & $4-3(108.211)-4$ & \\
\hline Alt Problem-1 & 1.13 & $4-17(119.993)-4$ & \\
\hline Alt Problem-1 & 1.14 & $4-8(120.000)-4$ & \\
\hline Alt Problem-1 & 1.15 & $4-3(108.211)-4$ & \\
\hline Alt Problem-1 & 1.16 & $\begin{array}{c}4-8(62.191)-36(53.208)- \\
4\end{array}$ & \\
\hline Alt Problem-1 & 1.17 & $4-36(106.417)-4$ & \\
\hline Alt Problem-1 & 1.18 & $\begin{array}{c}4-59(47.617)-23(69.720) \\
-4\end{array}$ & \\
\hline Alt Problem-1 & 1.19 & $\begin{array}{c}4-36(53.208)-8(60.733)- \\
4\end{array}$ & \\
\hline Alt Problem-1 & 1.20 & $4-47(108.371)-4$ & \\
\hline Alt Problem-2 & 2.1 & $\begin{array}{c}1-64(14.455)-26 \\
(69.020)-61(2.170)-1\end{array}$ & 0,08 \\
\hline
\end{tabular}


Ek 2 (devamı). Alt problem sonuçları: rotalar ve taşıma miktarları

\begin{tabular}{|c|c|c|c|}
\hline Alt Problem & Araç & Rota ve Taşıma Miktarları & $\begin{array}{l}\text { Çözüm } \\
\text { Süresi } \\
\text { (s.) }\end{array}$ \\
\hline Alt Problem-3 & 3.1 & $\begin{array}{c}6-52(49.716)-21 \\
(70.237)-6\end{array}$ & \multirow{14}{*}{14,76} \\
\hline Alt Problem-3 & 3.2 & $\begin{array}{c}6-7(15.370)-40(96.884) \\
-6\end{array}$ & \\
\hline Alt Problem-3 & 3.3 & $\begin{array}{c}6-63(67.979)-21 \\
(52.039)-6\end{array}$ & \\
\hline Alt Problem-3 & 3.4 & $\begin{array}{c}6-40(72.301)-21 \\
(47.618)-6\end{array}$ & \\
\hline Alt Problem-3 & 3.5 & $6-48(119.978)-6$ & \\
\hline Alt Problem-3 & 3.6 & $\begin{aligned} 6-33 & (48.772)-60 \\
& (71.272)-6\end{aligned}$ & \\
\hline Alt Problem-3 & 3.7 & $\begin{array}{c}6-60(44.921)-33 \\
(75.109)-6\end{array}$ & \\
\hline Alt Problem-3 & 3.8 & $6-52(119.963)-6$ & \\
\hline Alt Problem-3 & 3.9 & $\begin{array}{c}6-60(60.661)-48 \\
(59.361)-6\end{array}$ & \\
\hline Alt Problem-3 & 3.10 & $\begin{array}{c}6-63(39.537)-53 \\
(80.252)-6\end{array}$ & \\
\hline Alt Problem-3 & 3.11 & $6-53(109.378)-6$ & \\
\hline Alt Problem-3 & 3.12 & $6-40(120.020)-6$ & \\
\hline Alt Problem-3 & 3.13 & $\begin{array}{c}6-63(48.757)-33 \\
(71.207)-6\end{array}$ & \\
\hline Alt Problem-3 & 3.14 & $6-53(119.913)-6$ & \\
\hline Alt Problem-4 & 4.1 & $\begin{array}{c}12-25(38.430)-13 \\
(15.470)-12\end{array}$ & 0,05 \\
\hline Alt Problem-5 & 5.1 & $31-15(89.102)-31$ & \multirow{6}{*}{0,42} \\
\hline Alt Problem-5 & 5.2 & $\begin{array}{c}31-11(70.218)-42 \\
\quad(48.510)-31\end{array}$ & \\
\hline Alt Problem-5 & 5.3 & $\begin{array}{c}31-11(70.218)-42 \\
(48.510)-31\end{array}$ & \\
\hline Alt Problem-5 & 5.4 & $31-15(120.000)-31$ & \\
\hline Alt Problem-5 & 5.5 & $\begin{array}{c}31-11(70.218)-42 \\
(48.510)-31\end{array}$ & \\
\hline Alt Problem-5 & 5.6 & $\begin{array}{c}31-11(70.218)-42 \\
(48.510)-31\end{array}$ & \\
\hline
\end{tabular}


Köse Küçük M.,Çavdur F..: Zamn Pencr. Bölünmş Dağıtmlı Ar. Rot. Af. Sonr. Yrd. Mal. Dağ.Plan.

Ek 2 (devamı). Alt problem sonuçları: rotalar ve taşıma miktarları

\begin{tabular}{|c|c|c|c|}
\hline Alt Problem & Araç & Rota ve Taşıma Miktarları & $\begin{array}{l}\text { Çözüm } \\
\text { Süresi } \\
\text { (s.) }\end{array}$ \\
\hline Alt Problem-6 & 6.1 & $\begin{array}{c}32-18(41.396)-46 \\
(24.456)-54(54.166)-32\end{array}$ & \multirow{8}{*}{3.10} \\
\hline Alt Problem-6 & 6.2 & $\begin{array}{c}32-46(73.368)-18 \\
(41.396)-32\end{array}$ & \\
\hline Alt Problem-6 & 6.3 & $\begin{array}{c}32-2(45.850)-29 \\
(15.330)-14(47.302)-32\end{array}$ & \\
\hline Alt Problem-6 & 6.4 & $32-9(113.540)-32$ & \\
\hline Alt Problem-6 & 6.5 & $\begin{array}{c}32-50(104.179)-14 \\
(15.767)-32\end{array}$ & \\
\hline Alt Problem-6 & 6.6 & $32-18(82.792)-32$ & \\
\hline Alt Problem-6 & 6.7 & $\begin{array}{c}32-50(79.577)-54 \\
(36.413)-32\end{array}$ & \\
\hline Alt Problem-6 & 6.8 & $32-50(119.973)-32$ & \\
\hline Alt Problem-7 & 7.1 & $38-41(112.437)-38$ & \multirow{3}{*}{0.12} \\
\hline Alt Problem-7 & 7.2 & $\begin{array}{c}38-16(50.790)-41 \\
(56.218)-10(12.950)-38\end{array}$ & \\
\hline Alt Problem-7 & 7.3 & $\begin{array}{c}38-16(63.344)-41 \\
(56.218)-38 \\
\end{array}$ & \\
\hline Alt Problem-8 & 8.1 & $51-27(118.895)-51$ & \multirow{2}{*}{0,08} \\
\hline Alt Problem-8 & 8.2 & $51-55(6.965)-51$ & \\
\hline Alt Problem-9 & 9.1 & $\begin{array}{c}56-24(17.802)-22 \\
(84.366)-39(17.885)-56\end{array}$ & \multirow{4}{*}{0,8} \\
\hline Alt Problem-9 & 9.2 & $\begin{array}{c}56-24(10.057)-39 \\
(35.770)-30(60.585)-56\end{array}$ & \\
\hline Alt Problem-9 & 9.3 & $\begin{array}{c}56-58(73.622)-5(2.590) \\
-34(43.820)-56\end{array}$ & \\
\hline Alt Problem-9 & 9.4 & $\begin{array}{c}56-58(53.532)-22 \\
(48.493)-39(17.885)-56 \\
\end{array}$ & \\
\hline
\end{tabular}

